\title{
Amsterdaml'og \\ Strategies towards Zero-emission Energy through Geothermal Systems and Opportunities for Implementation of New Technologies
}

\author{
Karl-Heinz Wolf ${ }^{1}$, Andries Wever and Douglas Gilding
}

The high energy prices in the past year and the political and public demand for $\mathrm{CO}_{2}$ reduction show that geothermal energy can compete with conventional (i.e. carbon-based) energy sources in North-western Europe. The accelerated transformation of glasshouses in the Netherlands, from conventional to geothermal heating, shows that the economics are positive. In addition, mining geothermal water for city heating (Heerlen, the Hague) and the combination of geothermal with co-generation of heat and electricity are being implemented. More conventional geothermal applications are planned for the near future. However, this also means that conflicts of interests are to be expected. In a country with about seventeen million people living on only $34000 \mathrm{~km}^{2}$ land, the infrastructure is rather dense. Hence, the presence of geothermal constructions in densely populated areas requires effective development strategies and asset management concepts. At the same time, the availability of infrastructure also creates opportunities.

Conventional exploration in the Dutch sub-surface was aimed at hydrocarbons. Besides the giant Groningen Gasfield, many small oil and gas fields have been discovered and are being, or have been produced. Because of that, geophysical exploration data and appraisal wells cover a major part of the Netherlands. Most of the discovered fields are at depths over $1.5 \mathrm{~km}$ and by that in the depth range of geothermal interest, i.e. they provide data on geo-temperatures, aquifers and their sedimentological and reservoir characteristics. Evaluation of the well data resulted in a low resolution geothermal map of the country. However, for successful implementation, the subsurface needs systematic characterization in terms of reservoir existence, quality and flow, as well as geothermal gradients. Deliverability of the reservoir in terms of production/injection-flow and temperature are two major critical parameters for the economics of any geothermal project. Considering the dense infrastructure, both space at the surface and in the subsurface are relevant parameters that must be considered.

The new concepts for composite drilling of relatively shallow wells $(<2 \mathrm{~km})$ and novel ideas of (economically) combining hydrocarbon and geothermal exploration/exploitation at greater depths gives more opportunities; respectively smaller footprints and higher production temperatures. For the common shallow doublets, existing technology as already used over the last decades in France and Germany, are available. However, the combination of higher temperatures and pressures of deeper reservoirs needs the expertise of oil exploration combined with high temperature geothermal projects such as performed in Iceland and Italy.

New asset concepts include geothermal combined with electricity/heat cogeneration systems. When they are linked with $\mathrm{CO}_{2}$ co-injection, innovative applications of Enhanced and Unconventional Geothermal Systems can lead to zero-emission energy production. Feasibility studies and demonstration projects on combined co-injection and geothermal systems, including the development of carbon trade measures, will accelerate the use of these techniques.

\footnotetext{
1 Delft University of Technology, Department of Geotechnology, Stevinweg 1, 2628 CN, Delft, The Netherlands
} 


\section{(1) \\ Amsterdaml'og}

Geothermal systems are favorably exploited close to the customer, i.e. power plants and/or residential areas. Hence, spatial requirements for operations and management need be safeguarded. Moreover, HSE issues are more than ever of utmost importance, . especially when $\mathrm{CO}_{2}$ co-injection and high pressurized water/steam are part of the production process. This may lead to commotion and emotion, particularly when the NUMBY-effect impedes the planning and construction of a site. Within this light the technical concepts must be translated into societal acceptable solutions. This is a very difficult task in which social experts and technical professionals must work together in order to create a overall clearly positive social benefit. Another issue of collective and commercial thinking is; "do we have enough heat that can be mined" or "don't pass my geothermal fence at $2.5 \mathrm{~km}$ depth". In the Netherlands, the glasshouse commerce sparked a run on permits, very close to each other. This might create a "temporary" exhaustion of the reservoirs, undesirable or unacceptable interference, reservoir damage, and/or legal claims. Again, spatial requirements for operations and management need be safeguarded in all three dimensions of the earth. Various producing and injecting doublets in (close) proximity should strengthen each other and optimize by that the sweep efficiency of the reservoir. It may even be that it improves the pumping effectiveness, by using induced pressure drops. Here the reservoir geological and engineering knowledge used in oil industry are of paramount importance.

Last but not least, in many countries legal frameworks and exploration licenses are optimized and/or issued for hydrocarbon exploration and exploitation. Additionally, groundwater control for domestic purposes is safeguarded. These legal issues and rules by the authorities are not constructed with geothermal exploration and exploitation in mind. Geothermal energy requires a new framework on local, national and maybe even European level.

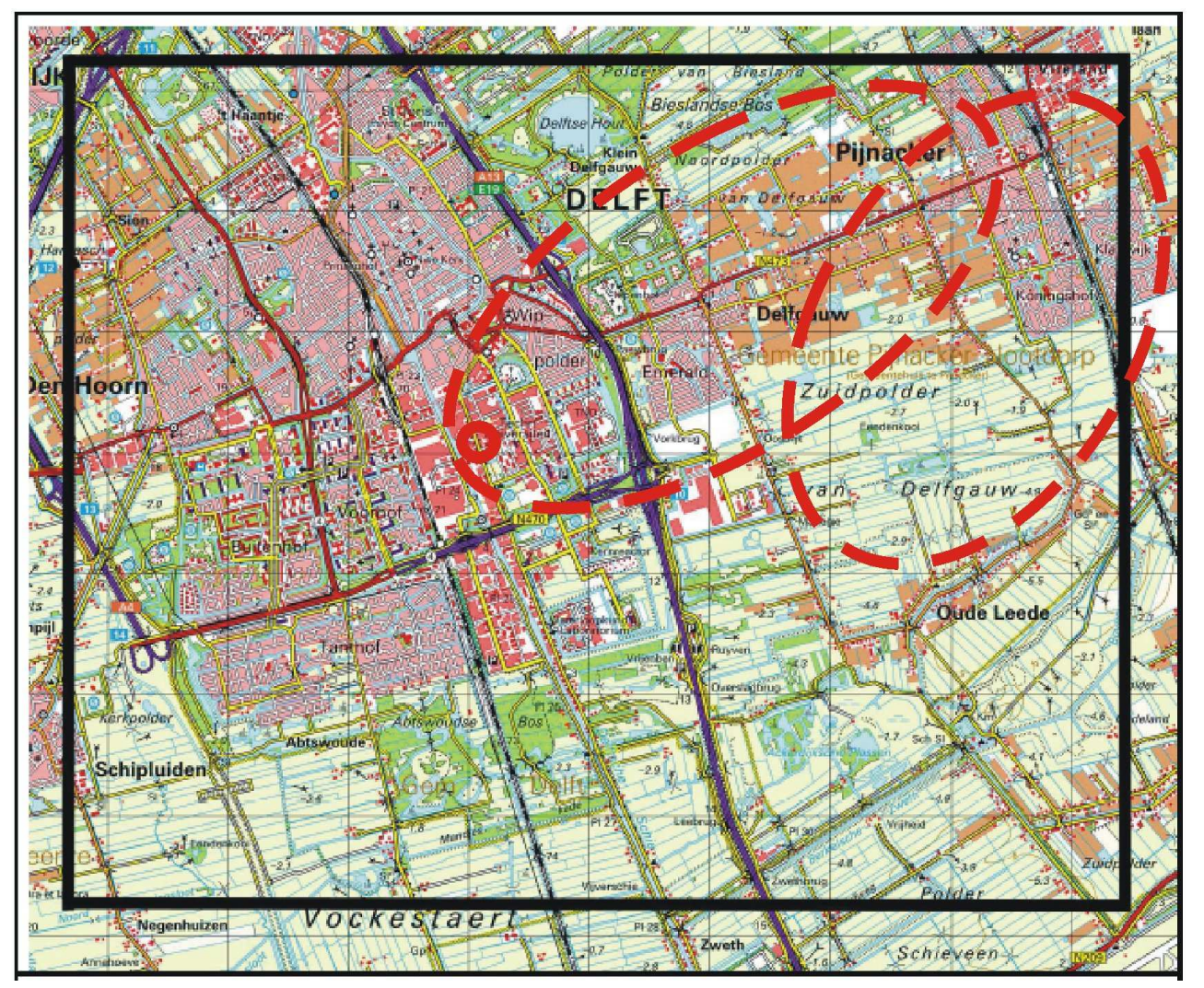

TU Delft concession for exploration: Conflicts of interest in a densely populated area with a high industrial activity. 